\title{
Regulation of gametogenesis and zoosporogenesis in U/va linza (Chlorophyta): comparison with Ulva mutabilis and potential for laboratory culture
}

\author{
Eleanor F. Vesty ${ }^{1}$, Ralf W. Kessler ${ }^{2}$, Thomas Wichard ${ }^{2}{ }^{*}$ and Juliet C. Coates ${ }^{1}{ }^{*}$ \\ ${ }^{1}$ School of Biosciences, University of Birmingham, Birmingham, UK \\ ${ }^{2}$ Institute for Inorganic and Analytical Chemistry, Jena School for Microbial Communication, Friedrich Schiller University Jena, Jena, Germany
}

Edited by:

Jo Ann Banks, Purdue University, USA

Reviewed by:

David Smyth, Monash University,

Australia

Christian Schulz, Ruhr-University

Bochum, Germany

\section{*Correspondence:}

Juliet C. Coates, School of

Biosciences, University of

Birmingham, Edgbaston, Birmingham

B15 2TT, UK

e-mail: j.c.coates@bham.ac.uk;

Thomas Wichard, Institute for

Inorganic and Analytical Chemistry,

Jena School for Microbial

Communication, Friedrich Schiller

University Jena, Lessingstraße 8,

07743 Jena, Germany

e-mail: thomas.wichard@uni-jena.de
Green Ulvophyte macroalgae represent attractive model systems for understanding growth, development, and evolution. They are untapped resources for food, fuel, and high-value compounds, but can also form nuisance blooms. To fully analyze green seaweed morphogenesis, controlled laboratory-based culture of these organisms is required. To date, only a single Ulvophyte species, Ulva mutabilis Føyn, has been manipulated to complete its whole life cycle in laboratory culture and to grow continuously under axenic conditions. Such cultures are essential to address multiple key questions in U/va development and in algal-bacterial interactions. Here we show that another Ulva species, U. linza, with a broad geographical distribution, has the potential to be grown in axenic culture similarly to $U$. mutabilis. U. linza can be reliably induced to sporulate (form gametes and zoospores) in the laboratory, by cutting the relevant thallus tissue into small pieces and removing extracellular inhibitors (sporulation and swarming inhibitors). The germ cells work as an ideal feed stock for standardized algae cultures. The requirement of $U$. linza for bacterial signals to induce its normal morphology (particularly of the rhizoids) appears to have a species-specific component. The axenic cultures of these two species pave the way for future comparative studies of algal-microbial interactions.

Keywords: green algae, gametogenesis, zoosporogenesis, morphogenesis, life cycle, algal-bacterial interactions, axenic culture, sporulation inhibitor

\section{INTRODUCTION}

The growth and development of land plants has been extensively studied and representative model systems have been developed for molecular genetic studies in several major clades, for example, Arabidopsis for dicots, Oryza/Brachypodium for monocots, Selaginella for lycophytes, and Physcomitrella for early evolving Bryophytes (The Arabidopsis Genome Initiative, 2000; Goff et al., 2002; Rensing et al., 2008; Banks et al., 2011; Girin et al., 2014). This has enabled translation of the understanding of basic biological principles of plant development and evolution from models to crops (Irish and Benfey, 2004; Rensink and Buell, 2004; Coudert et al., 2010; Spannagl et al., 2011; Orman-Ligeza et al., 2014), thus improving the potential of crop plants for food and biofuel, to meet the challenges of population- and climate change. Green macroalgae (seaweeds) represent a new group of organisms with great potential for tackling the challenges of food- and fuel-security (Dibenedetto, 2012), which also cause significant environmental problems in the form of green tides and biofouling (Callow and Callow, 2006a,b; Smetacek and Zingone, 2013). However, unlike land plants, green seaweeds are under-exploited as model organisms, thus the understanding of their mechanisms of growth and development is currently severely limited.

The reason for this under-exploitation is partly due to the extreme challenges faced when growing green seaweeds under sterile laboratory conditions. It has been demonstrated for several species of green algae that the epiphytic bacterial populations with which they naturally associate are absolutely required for correct development and subsequent morphogenesis (Matsuo et al., 2003; Marshall et al., 2006; Spoerner et al., 2012). Thus, the axenic cultures that are normally required for molecular genetic/functional genomic studies in a model organism, such as transformation systems and genome/transcriptome sequencing are not straightforward to develop for green seaweeds. The greatest progress has been made with one species of Chlorophyte macroalga, Ulva mutabilis, [which is native to Southern Cost of Portugal and originally collected by Føyn (1958)], with (i) an established laboratory culture protocol (Stratmann et al., 1996; Wichard and Oertel, 2010), (ii) a collection of developmental mutants (Løvlie, 1968), (iii) definition of bacterial species and partially purified substances that are required for proper morphogenesis (Spoerner et al., 2012) and (iv) the isolation of factors that prevent the breakdown of leafy thallus tissue into unicellular spores/gametes (zoosporogenesis and gametogenesis, respectively, collectively "sporulation"; Nilsen and Nordby, 1975; Stratmann et al., 1996). This has paved the way for truly axenic culture of $U$. mutabilis, which will enable sequencing of this species (Spoerner et al., 2012). One general issue with seaweed culture is inducing transition between generations via unicellular cell types (gametes or zoospores). U. mutabilis produces substances that inhibit the induction of gamete- and spore-formation, 'sporulation inhibitors' (SI; the glycoprotein SI1 and the low molecular weight SI-2; Stratmann etal., 1996). A third substance, the 'swarming inhibitor' (SWI) prevents gamete 
release after induction has occurred (Wichard and Oertel, 2010). Gamete induction and release can be induced in vegetative $U$. mutabilis thallus by washing and tissue fragmentation, and similarly (albeit more slowly) in U. lactuca (Wichard and Oertel, 2010). A similar method may also work to induce spores in U. prolifera, as tissue fragmentation into disks leads to spore formation (Gao et al., 2010).

Ulva is an economically important genus, and therefore merits a deeper understanding of its growth and developmental mechanisms at the molecular level (Wichard et al., under review). Ulva is a food source (Nisizawa et al., 1987; Tabarsa et al., 2012) and a potential source of biomass for fuel production (Bruhn et al., 2011). However, Ulva also forms nuisance algal blooms (Blomster etal., 2002; Nelson et al., 2003; Hiraoka et al., 2004; Leliaert etal., 2009; Smetacek and Zingone, 2013) and is a major biofouler (Callow and Callow, 2006a). Although certain worldwide abundant species such as the sea lettuce $U$. rigida (e.g., RFU_77) can be cultured under standardized conditions (Alsufyani etal., 2014), sporulation could not easily be synchronously induced as in tubular Enteromorpha-like morphotypes of the genus Ulva (Nilsen and Nordby, 1975; Stratmann et al., 1996).

In this paper, we sought to discover whether Ulva species other than $U$. mutabilis could be cultured axenically in the laboratory, and whether the signals regulating Ulva sporulation, morphogenesis, and development are conserved between species. We chose $U$. linza, a cosmopolitan intertidal alga found, e.g., along the coastlines of the UK and in the Yellow Sea (China; Brodie et al., 2007; Xu et al., 2013), which is a well-established model for biofouling research (Callow and Callow, 2006b) and has a partly characterized microbiome (Marshall et al., 2006). We showed that $U$. linza has the potential for standardized laboratory culture. We also highlight potential species-specific requirements for the bacterial signals required for correct morphogenesis.

\section{MATERIALS AND METHODS SAMPLING AND CULTIVATION OF UIva Algal strains}

Haploid gametophytes from the fast-growing developmental mutant "slender" (sl) of U. mutabilis Føyn (mating type $\mathrm{mt}+$ ) were used for all comparative studies with U. linza (Føyn, 1958; Løvlie, 1964; Fries, 1975). Vegetative and fertile sporophytic $U$. linza plants were collected in March 2013, from Llantwit Major, South Wales $\left(51^{\circ} 40^{\prime} \mathrm{N} ; 3^{\circ} 48^{\prime} \mathrm{W}\right)$. Gametogenesis and sporogenesis was induced by chopping the harvested tissue using a Zyliss ${ }^{\circledR}$ Smart Clean Food Chopper.

\section{Bacterial strains}

Roseobacter sp. MS2 (Genbank EU359909) and Cytophaga sp. MS6 (Genbank EU359911) were cultivated in marine broth medium at $20^{\circ} \mathrm{C}$ on an orbital shaker. They were originally isolated from U. mutabilis (Spoerner et al., 2012) and stocks are stored in glycerol at $-80^{\circ} \mathrm{C}$.

\section{Cultivation conditions}

Gametophytes of $U$. mutabilis and $U$. linza were raised parthenogenetically from unmated gametes or from zooids derived from sporophytes under the standard conditions (Stratmann et al., 1996). Small germlings were grown attached to the bottom of sterile culture flasks with gas-permeable screw caps containing $100 \mathrm{~mL}$ Ulva culture medium (UCM) without antibiotics. The medium for $U$. mutabilis was routinely supplemented with the two bacterial symbionts of the algae, Roseobacter sp. MS2 and Cytophaga sp. MS6 to secure normal thallus morphogenesis. Until fertility the medium was completely exchanged weekly. Later, the medium was changed only partially (50\%) to avoid premature induction of gametogenesis. The medium for experimental $U$. linza was either unsupplemented (axenic), supplemented with MS2 and MS6, or its natural bacterial flora.

Ulva mutabilis and experimental $U$. linza were cultivated in $\mathrm{UCM}$ in a $17: 7 \mathrm{~h}$ light/dark regime at $20^{\circ} \mathrm{C}$ with an illumination of 60-120 $\mu \mathrm{mol}$ photons $\mathrm{m}^{-2} \mathrm{~s}^{-2}$ (50\% GroLux, 50\% day-light fluorescent tubes; OSRAM, München, Germany) and no additional aeration. Freshly collected $U$. linza thalli were washed and kept in UCM (Stratmann et al., 1996) in large tanks and boxes ( $>1 \mathrm{~L}$ ), in a Sanyo MLR-351 growth cabinet with Osram Lumilux Cool White L36W/840 (36 watt, $4 \mathrm{ft}$ ) tubes at an illumination of $50 \mu \mathrm{mol} \mathrm{m}{ }^{-2} \mathrm{~s}^{-1}$.

\section{BIOASSAYS OF EXTRACTED SPORULATION INHIBITORS Chemicals}

For the extraction of the SI (SI-1, SI-2), tris (hydroxymethyl) aminomethane (Tris) was purchased from VWR (Darmstadt, Germany), $\mathrm{HCl}(37 \%)$, and EDTA ( $\geq 99.9 \%$, p.a., ACS) were obtained from Roth (Karlsruhe, Germany). Phenol was purchased from Alfa Aeser (Karlsruhe, Germany), ethanol (99.9\%, LiChroSolv) from Merck KGaA (Darmstadt, Germany) and acetone from Fluka (Sigma-Aldrich, Taufkirchen, Germany). Instant Ocean was obtained from Aquarium Systems (Sarrebourg, France). All solutions were prepared with ultrapure water purified by a reverse osmosis system (TKA, Niederelbert, Germany).

\section{Preparation of crude extracts for purification of the sporulation inhibitors (SI-1, SI-2)}

The established extraction protocols of the SI-1 and SI-2 by Stratmann etal. (1996) were slightly modified and applied to both $U$. mutabilis and $U$. linza.

For the extraction of the SI-1 from the growth medium, $500 \mathrm{~mL}$ of medium from 3 to 4 week old axenic $U$. mutabilis cultures was stirred with $50 \mathrm{~mL}$ phenol (saturated with $100 \mathrm{mmol} \mathrm{L}^{-1}$ Tris$\mathrm{HCl}, 1 \mathrm{mmol} \mathrm{L}^{-1}$ EDTA, pH 7.5) in a $1 \mathrm{~L}$ two-neck round-bottom flask for $20 \mathrm{~min}$ at $20^{\circ} \mathrm{C}$. After centrifugation $(3800 \mathrm{~g}, 10 \mathrm{~min})$ the phenol phase was transferred into plastic tubes. The extraction was repeated once and the phenol phases were combined. After re-extracting with $100 \mathrm{~mL} 10 \mathrm{mmol} \mathrm{L}^{-1}$ Tris- $\mathrm{HCl}$ ( $\mathrm{pH} 8.0$ ), the phenol phase was mixed with three volumes of acetone and subsequently incubated for $30 \mathrm{~min}$ at $-20^{\circ} \mathrm{C}$. The precipitate was collected by centrifugation $\left(3800 \mathrm{~g}, 20 \mathrm{~min}, 0^{\circ} \mathrm{C}\right)$ and washed three times with pre-cooled ethanol $\left(-20^{\circ} \mathrm{C}\right)$. After drying in the vacuum, the precipitate was suspended in $100 \mathrm{mmol} \mathrm{L}^{-1}$ Tris- $\mathrm{HCl}$ $(\mathrm{pH} 8.0)$ and stored at $-20^{\circ} \mathrm{C}$.

For the extraction of the SI- 1 from the thallus, $2 \mathrm{~g}$ of minced Ulva sp. thalli was washed with UCM and frozen with liquid nitrogen. After grinding the thalli with a pestle, the powder was thawed 
and resuspended directly in $5 \mathrm{~mL}$ of $50 \mathrm{mmol} \mathrm{L}^{-1}$ Tris- $\mathrm{HCl}(\mathrm{pH}$ 8.0). This was repeated once and subsequently thalli were mixed in $2 \mathrm{~mL}$ of $10 \mathrm{mmol} \mathrm{L}^{-1}$ Tris- $\mathrm{HCl}(\mathrm{pH} 8.0)$ and $2 \mathrm{~mL}$ phenol (saturated with $100 \mathrm{mmol} \mathrm{L}^{-1}$ Tris- $\mathrm{HCl}, 1 \mathrm{mmol} \mathrm{L}^{-1}$ EDTA, $\mathrm{pH}$ 7.5) at $60^{\circ} \mathrm{C}$ for $30 \mathrm{~min}$. The extraction was repeated once and the phenol phase was washed with $4 \mathrm{~mL} 10 \mathrm{mmol} \mathrm{L}^{-1}$ Tris- $\mathrm{HCl}(\mathrm{pH}$ 8.0) and mixed with three volumes of acetone for $\geq 30 \mathrm{~min}$ at $-20^{\circ} \mathrm{C}$. After drying in a vacuum, the precipitate was suspended in $100 \mathrm{mmol} \mathrm{L}{ }^{-1}$ Tris- $\mathrm{HCl}(\mathrm{pH} 8.0)$ and stored at $-20^{\circ} \mathrm{C}$.

For the extraction of the SI- 2 from the fluid in between the bilayered thallus, Ulva thalli were washed for $15 \mathrm{~min}$ with ultrapure water and blotted with paper. One gram of thalli was suspended in $4 \mathrm{~mL} 10 \mathrm{mmol} \mathrm{L}^{-1}$ Tris-HCl ( $\mathrm{pH} \mathrm{8.0)}$ and cut into single-layered fragments with a chopper. After centrifugation $(3800 \mathrm{~g}, 10 \mathrm{~min})$, the buffer containing SI-2 was passed through cellulose acetate filters and stored at $-20^{\circ} \mathrm{C}$ (Stratmann et al., 1996).

\section{Bioassay-guided testing of sporulation inhibitors}

Fertile Ulva sp. thalli were harvested before noon and intensively washed with half-concentrated Instant Ocean for $15 \mathrm{~min}$. According to Stratmann et al. (1996) the induction efficiency (i.e., proportion of cells differentating into gametangia) increases dramatically if sporulation is induced during the G1-cell-cycle phase, which happens before noon in synchronized cultures of $U$. mutabilis. We assumed the same was true for $U$. linza and, indeed, this was the case.

After chopping the thalli, Ulva fragments were washed twice in a fine sieve. The fragments $(n=70 \pm 30)$ were transferred into 96 multiwell dishes (Nunc, Roskilde, Denmark) with $100 \mu$ l UCM for survey of gametogenesis. The concentration of the SIs was measured via dilution series of the partly purified compounds with UCM according to Stratmann et al. (1996). Due to the nature of the discrete dilution series, variance of measurement also depends on the interval of the dilution steps: a dilution series of six steps ranking from 150 units to 1 unit of the respective inhibitor was performed. One unit of the SI-1 and SI-2 is hereby defined as the concentration that inhibits completely the gametogenesis of a mature alga (i.e., fragmented thallus) completely in $1 \mathrm{~mL}$ of UCM for 3 days at $20^{\circ} \mathrm{C}$ upon induction. In parallel, samples with Tris- $\mathrm{HCl}$ (negative control) and with defined known amounts of SI (positive control) were tested. After 3 days of incubation the sporulation rates were determined under a Leica DMIL LED microscope equipped with a DFC 280 camera (Leica, Solms, Germany). The one-way Analysis of Variance (ANOVA) and the subsequent Tukey post hoc tests were performed by Minitab 16 Statistical Software (2010; State College, PA, USA: Minitab, Inc.).

\section{PREPARATION OF AXENIC CULTURES}

For the preparation of axenic cultures of $U$. linza, gametes were purified from accompanying bacteria based on the protocol developed for U. mutabilis (Spoerner et al., 2012): purification was performed by phototactic movement of freshly released gametes through a narrow horizontal capillary (see also review by Wichard et al., under review) toward a light source, under strictly sterile conditions in a laminar flow hood. Sterile Pasteur pipettes with $15 \mathrm{~cm}$ capillaries were prepared; gametes swim to the top of the pipettes, where they are collected and applied for next run of purification through a further Pasteur pipette (Figure 3). In general three runs are necessary to purify the gametes form the bacteria. The final preparations of axenic gametes were routinely tested for axenicity by plating aliquots on marine broth agar (Roth, Karlsruhe, Germany) and checking for absence of bacterial colony formation.

\section{BIOASSAY-GUIDED TESTING OF MORPHOGENESIS INDUCING BACTERIA}

Standard bioassays of the activities of the bacterial morphogenetic factors were performed in sterile $50 \mathrm{~mL}$ plastic tissue-culture flasks (Nuclon Surface, Nunc Int.) for both U. linza and U. mutabilis (control strain). $10 \mathrm{~mL}$ sterile UCM was inoculated with $\sim 1000$ freshly prepared axenic gametes. After incubation overnight at $20^{\circ} \mathrm{C}$ in the dark, gametes randomly attached to the bottom of the flask. Axenic gametes of $U$. linza were inoculated with a combination of Roseobacter sp. and Cytophaga sp. (cell density $10^{4}$ cells $\mathrm{mL}^{-1}$ ) or with the natural bacterial community. As a negative control, one flask was left without any bacteria for the complete period of the experiment. The flasks were cultured under standard light: dark conditions and analyzed under the inverted microscope during the next 21 days. The observed qualitative features were [as described by Spoerner et al. (2012)]: the presence of bubble-like cell wall protrusions; degenerating blade cells and differentiated rhizoid cells.

\section{RESULTS}

\section{INDUCTION OF GAMETOGENESIS AND ZOOSPORANGENESIS}

Cutting gametophyte blades of $U$. linza into small pieces using a chopper can induce full gamete formation and release of gametes in the morning of the third day, upon an additional medium change (Figure 1). On the day of induction and during the next day, the phenotype of the blade cells does not change visibly, and the orientation of the chloroplasts stays perpendicular to the light for optimal energy uptake (Figures 1A,B). During the second day after induction, the cells further differentiate into gametangia containing about 16 progametes, which mature during the following night into fully developed gametes ready for swarming (Figures 1C,D). If gametogenesis was induced in a small volume of UCM, the fully developed gametes were not released in the next morning, despite illumination, until the medium was changed again, which implies the accumulation of a SWI as reported in U. mutabilis (Wichard and Oertel, 2010; Figure 1C). In addition, applying the same protocol to sporophyte blade tissue leads to spore induction and release (Figures 1E,F) as observed in $U$. mutabilis. To verify the culture conditions in the laboratory, Ulva was grown under quasi-natural conditions, where the medium was turned over on a continuous orbital shaker: spontaneous gametogenesis was not observed until an age of 3-4 weeks or even later as previously reported by Stratmann et al. (1996).

\section{EXTRACTION OF SPORULATION INHIBITORS FROM U. linza}

The results in Section "Induction of Gametogenesis and Zoosporangenesis" imply that sporulation in $U$. linza has similar regulation to sporulation in $U$. mutabilis and involves the removal of SI (=induction) and SWIs (=release of gametes), although they belong to different clades of Ulva (Guidone et al., 2013). To 


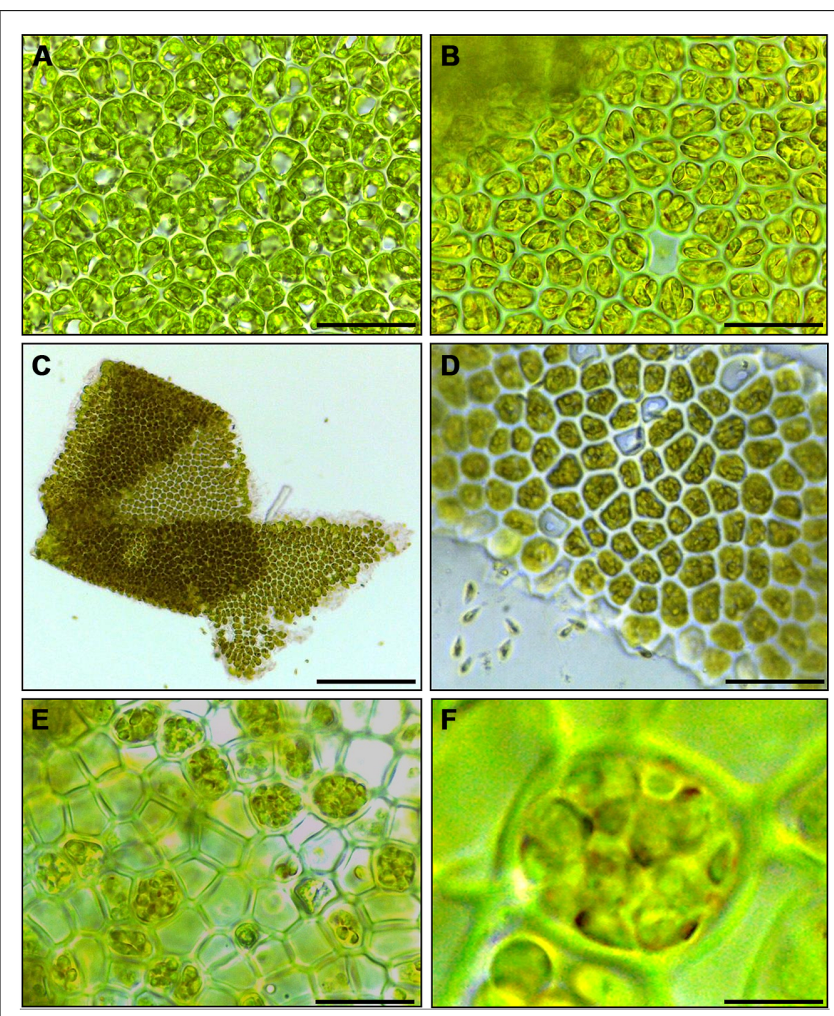

FIGURE 1 | Induction of gametogenesis and zoosporogenesis in Ulva linza. Phenotypic changes of blade cells during gametogenesis and gamete release. (A) Blade cells $24 \mathrm{~h}$ after induction resemble uninduced blade cells: cells are square and often in transverse rows. (B) $48 \mathrm{~h}$ after induction, blade cells differentiate into gametangia containing finally 16 progametes, which mature during the following night into fully developed gametes ready for swarming. (C,D) Gametes are discharged in the morning of the third day. (E) Discharged sporangia and (F) zoospores within a sporangium are shown. Gametophytes (A-D) and sporophytes (E,F) were grown under standard conditions (Scale bars: A,B,D $=25 \mu \mathrm{m} ; \mathbf{C}=140 \mu \mathrm{m}$, $\mathbf{E}=16 \mu \mathrm{m}, \mathbf{F}=4 \mu \mathrm{m})$.

investigate whether gamete induction in $U$. linza requires the same or similar factors as in U. mutabilis, we partially purified SI from both $U$. mutabilis and freshly collected $U$. linza samples using the previously established method (Stratmann et al., 1996) and crosstested them. We showed that $U$. linza produces SI that work interchangeably with $U$. mutabilis during gametogenesis: both types of U. mutabilis $\mathrm{SI}\left(\mathrm{SI}_{\mathrm{M}} 1\right.$ and $\left.\mathrm{SI}_{\mathrm{M}} 2\right)$ were each able to inhibit gamete production in $U$. linza and $U$. mutabilis (Figure 2), albeit to a lesser extent (for medium-derived $\mathrm{SI}_{\mathrm{M}} 1$ and between-cell-layers $\mathrm{SI}_{\mathrm{M}} 2$ ) in $U$. linza. Conversely, $U$. linza $\mathrm{SI}\left(\mathrm{SI}_{\mathrm{L}} 1\right.$ and $\mathrm{SI}_{\mathrm{L}}$ 2) were each able to inhibit gamete formation in both Ulva species tested (Figure 2).

In detail, the determined biologically active concentration depends to some extent on the target species: $\mathrm{SI}_{\mathrm{L}} 1$ accounts for $9.4 \pm 6.8$ units $\mathrm{mL}^{-1}$ tested on $U$. linza, which was equal to 5 units $\mathrm{mL}^{-1}$ tested on $U$. mutabilis and thus less is less active toward $U$. mutabilis, although the difference is not statistically significant due to the high variance of the biological replicates (one-way ANOVA followed up by Tukey post hoc tests with an overall significance level of $5 \%$ ). Moreover, $\mathrm{SI}_{\mathrm{M}} 2$ is significantly (about 10 times) more active when applied to $U$. mutabilis rather than to U. linza,

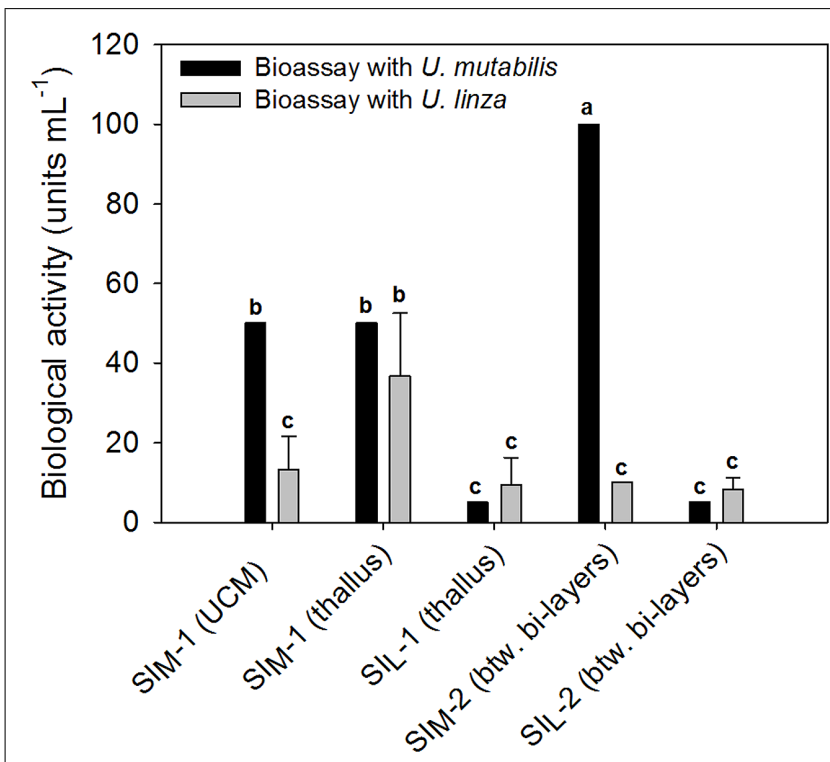

FIGURE 2 | Quantification of the sporulation inhibitors (SI), $\mathrm{SI}_{\mathrm{M}}$ and $\mathrm{SI}_{\mathrm{L}}$, extracted from $\boldsymbol{U}$. mutabilis and $\boldsymbol{U}$. linza, respectively. $\mathrm{SI}_{\mathrm{M}^{-1}}$ was extracted from both the U/va culture medium (UCM) and the thallus, whereas $\mathrm{SI}_{\mathrm{L}}-1$ only from the thallus. The inhibitors were then cross-tested on both Ulva species (black bars $=U$. mutabilis, gray bars $=U$. linza). Activity of the inhibitors is given in units $\mathrm{mL}^{-1}$ (mean $\pm \mathrm{SD}, n=3$ ). One unit of the SI-1 and SI-2 is defined as the concentration that inhibits the gametogenesis/zoosporogenesis of a mature alga completely in $1 \mathrm{~mL}$ of UCM for 3 days at $20^{\circ} \mathrm{C}$ upon induction. One-way ANOVA was performed to determine statistical significance. Tukey's test was used to determine which groups differ (significance level $=5 \%$ ), indicated by the letters $a, b$ and $\mathrm{c}$.

but the $\mathrm{SI}_{\mathrm{L}} 2$ does not show any species-specific differences in its inhibitory activity (Figure 2).

\section{GENERATION OF FEEDING STOCK BY GAMETE PURIFICATION}

Understanding the regulation of $U$. linza allows building up of a feedstock for further standardized cultivation, similarly to $U$. mutabilis. $U$. linza gametes from a single blade (i.e., all the same mating type) isolated upon induction of gametogenesis were able to germinate parthenogenetically to form blades. Therefore, we tried to purify $U$. linza gametes for axenic culture and to set up cultures forming thalli parthenogenetically with a controlled microbiome. As U. mutabilis can be put into axenic culture by purifying gametes via their strong and rapid phototactic response (Spoerner et al., 2012), we investigated whether U. linza gametes could behave (and therefore be purified) in the same way. We showed that $U$. linza gametes can be subject to purification in a very similar manner to $U$. mutabilis, over a very similar time frame (Figure 3). The gametes were demonstrated to be axenic by inoculation of the medium in which the purified gametes were residing onto Petri dishes: after the third purification run in Pasteur pipettes the gamete containing medium was free of bacteria (Figure 3C).

\section{BACTERIA INDUCED MORPHOGENESIS}

As epiphytic bacteria are required for correct morphology in both U. mutabilis and U. linza (Fries, 1975; Marshall et al., 2006; 


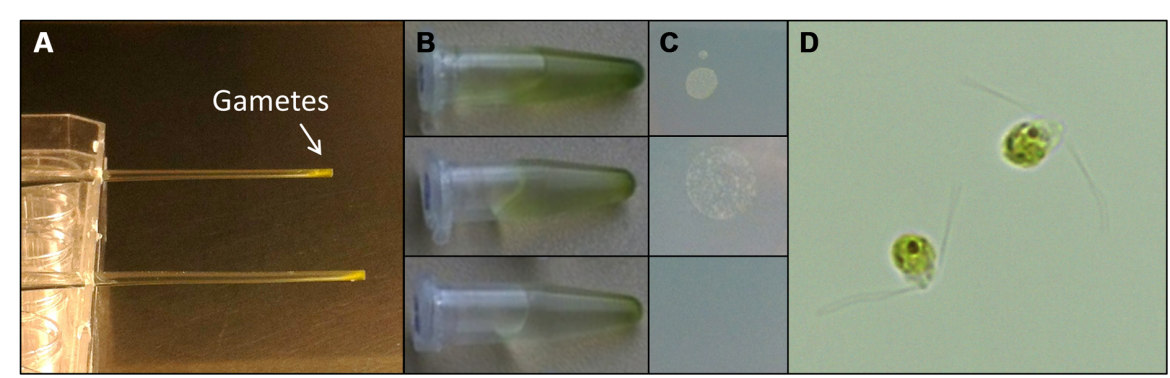

FIGURE 3 | Purification of $\boldsymbol{U}$. linza gametes from accompanying bacteria. Gametes are harvested upon medium change; capitalizing on their movement toward the light. Then collected gametes are purified in capillary pipettes several times (A). The purifications can be quickly tested by placing a drop $(10 \mu \mathrm{L})$ of the gamete solution $(\mathbf{B})$ on marine broth agar plates (C). In general three purification steps are sufficient to separate the bacteria from the gametes. Bacterial colonies forming on marine broth agar plates could be observed after two purification steps but not after the third one (C). Purified bi-flagellated gametes $(3 \mu \mathrm{m})$ are shown (D).
Spoerner et al., 2012), we tested whether U. mutabilis bacteria could drive the correct development of $U$. linza. Gametes were seeded in culture either axenically (purified, no bacteria), with the normal complement of $U$. linza epiphytes (i.e., gametes induced but not purified), or with the two species of bacteria known to restore morphogenesis to axenic U. mutabilis, namely Cytophaga sp. MS2 and Roseobacter sp. MS6 (Spoerner et al., 2012). Axenic $U$. linza formed an undifferentiated mass of cells reminiscent of axenic $U$. mutabilis, with very little cell elongation or longitudinal cell division, compared to non-axenic controls (Figure 4). The size of the structure formed was larger than for U. mutabilis. However, the callus-like morphology contained the typical colorless protrusions from the exterior cell walls as observed in axenic cultures of U. mutabilis (Spoerner et al., 2012), Enteromorpha compressa and E. linza (Fries, 1975).

Addition of Roseobacter sp. and Cytophaga sp. to axenic U. linza restored blade growth/elongation and rhizoid growth, and the bacteria clustered around the rhizoid as seen in U. mutabilis. However, the combination of Roseobacter sp. and Cytophaga sp. were unable to restore wild type rhizoid morphology to $U$. linza. The rhizoids
A

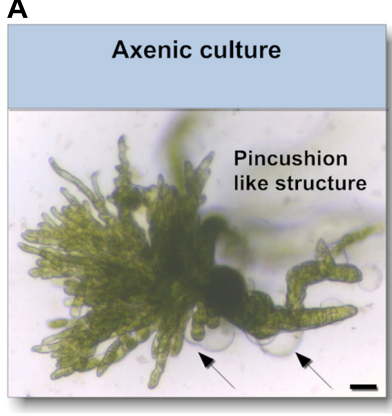

D

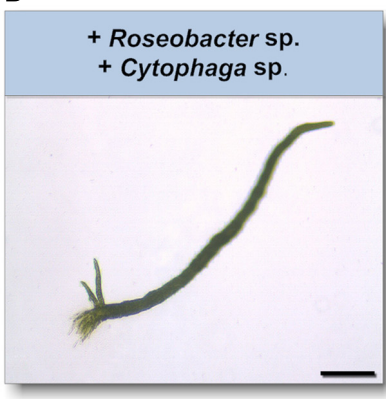

B

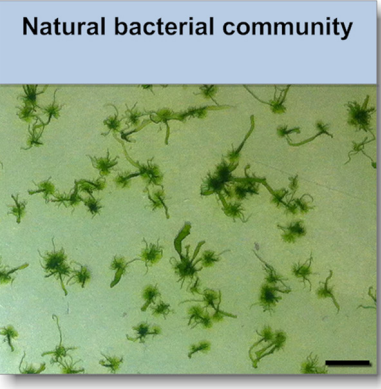

E

C

Natural bacterial community

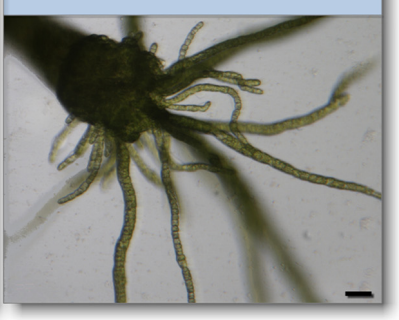

$\mathbf{F}$

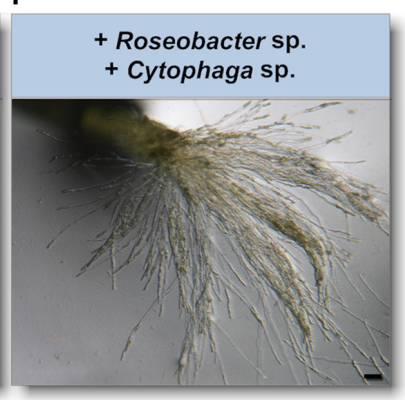

FIGURE 4 | Survey of the effects of know morphogenesis inducing bacteria on $\boldsymbol{U}$. linza. (A) Phenotype of an axenic $U$. linza gametophyte after 3 weeks cultivation with few initial thallus stages. Algae grow parthenogenetically from axenic gametes (scale bar $=25 \mu \mathrm{m}$ ). Arrows indicate the typical colorless protrusions from the exterior cell walls of axenic cultures. (B,C) Axenic gametes with the natural microbiome develop into a normal plant (scale bar $=1 \mathrm{~cm}$ in (B) and $50 \mu \mathrm{m}$ in (C). (D,E) Addition of Roseobacter $\mathrm{sp}$. and Cytophaga sp. induces blade and rhizoid formation and bacterial concentrate at the rhizoids (scale bar $\mathbf{D}=1 \mathrm{~mm}, \mathbf{E}=50 \mu \mathrm{m}$ ). (F) However, rhizoid formation seems to be incomplete in comparison of the $U$. linza grown in natural bacterial community even after 5 weeks compared to (C) (scale bar $=50 \mu \mathrm{m}$ ). 
formed were extremely numerous and thin, largely only one cell thick (Figures 4E,F). In addition, the growth of $U$. linza within this tripartite community was significantly slower than the growth of the "sl" mutant of U. mutabilis (3 weeks to achieve maturity; Løvlie, 1964) and the $U$. linza in a natural community.

\section{DISCUSSION}

\section{GAMETOGENESIS AND SPOROGENESIS CAN BE INDUCED IN $\boldsymbol{U}$. linza}

We have shown that $U$. linza gametes (and zoospores) can now be reproducibly induced by cutting thallus tissue and removing extracellular inhibitors (SI-1, SI-2), as in U. mutabilis. This shows that there is potential for laboratory culture of a cosmopolitan Ulva species with worldwide distribution including in the UK, which is an established model for biofouling research and algalbacterial interactions. A lack of gamete release when gametes are induced in a small volume of culture medium implies the existence of a SWI, as in U. mutabilis. The presumed release of the SWI has to be further investigated and compared with $U$. mutabilis to see whether the SWIs are exchangeable at the same concentration or whether they are even the same substance.

\section{Ulva linza PRODUCES SPORULATION INHIBITORS}

We have partially purified $\mathrm{SI}\left(\mathrm{SI}_{\mathrm{L}} 1\right.$ and $\left.\mathrm{SI}_{\mathrm{L}} 2\right)$ from $U$. linza and compared their activity to the $\mathrm{SI}_{\mathrm{M}}$ previously isolated from U. mutabilis (Nilsen and Nordby, 1975; Stratmann et al., 1996). $U$. linza $\mathrm{SI}_{\mathrm{L}}$ works interchangeably with $U$. mutabilis during gametogenesis. U. mutabilis sporulation inhibitor inhibited gametogenesis in both $U$. linza and $U$. mutabilis, but to a lesser extent in U. linza. Conversely, U. linza SI inhibited gamete formation in both Ulva species. This demonstrates that the tested SIs are not species-specific and indicates that $U$. mutabilis and $U$. linza use similar signals to regulate induction and release of both unicellular life cycle stages. The tendency is that higher amounts of SI are necessary to inhibit the sporulation of the opposite Ulva species, indicating that the isolated SIs from both species are probably not identical and may differ slightly in their structure-activity relationship.

There were high variances between biological replicates with $U$. linza and this highlights the advantages of standardized culture conditions with synchronized algae. Whereas the variances were high for the bioassays with the $U$. linza due to its potentially varying age, variances of the inhibitory effects on the gametogenesis of $U$. mutabilis were so small they were not measurable within the resolution of the dilution series for three biological replicates conducted in parallel, (i.e., no SD is seen in Figure 2).

Compared to Stratmann et al. (1996), the extracted yield of inhibitor from the UCM (i.e., biological activity) was in general lower than previously reported. This can be explained with the lower cell densities that were used in our study. The $\mathrm{SI}_{\mathrm{L}} 1$ was only extracted from the thalli of vegetatively growing $U$. linza cultures and could not be detected in the UCM of U. linza, in contrast to U. mutabilis laboratory cultures. This is partly due to the fact that bacteria of the undefined microbiome of the collected $U$. linza samples have most likely digested the SI, as was also shown in natural U. mutabilis samples (Stratmann et al., 1996).

The observation that $U$. linza and $U$. mutabilis share similar SI and perception systems cannot be generalized within the entire
Ulva genus, as the $\mathrm{SI}_{\mathrm{M}} 1$ was not effective on $U$. rigida (Stratmann etal., 1996). Because the morphology of the distromatic thalli (broad thalli with no hollow parts) of $U$. rigida is very different to the monostromatic thalli of $U$. linza and $U$. mutabilis (broad or ribbon like thalli with hollow parts), further studies need to investigate the underlying evolutionary processes and verify whether, e.g., life-cycle-regulating factors are clade-specific in the genus of Ulva, e.g., in the compressa/pseudocurvata/mutabilis group versus the rigida group (Guidone et al., 2013). Recently, it was suggested that apparently clade-specific biosynthetic pathways are used to transform polyunsaturated fatty acids into oxylipins (Alsufyani et al., 2014). Taking into account that an excess of SI-1, a cell-wall glycoprotein, is released into the environment, inhibitors might regulate the germ cell formation of closely related Ulva species in, e.g., tidal ponds or during green tides. This inter-species regulation might become a fortiori important, as waterborne breakdown products of the protein can still possess inhibitory activities (Stratmann et al., 1996; Kessler, personal communication).

In nature, the induction of sporulation might be triggered by segmentation as potentially observed by Gao et al. (2010) during green tides. Certainly sporulation events also occur even without fragmentation, whenever the SIs are either not produced or perceived in Ulva's life cycle (Stratmann et al., 1996), which might explain the underlying mechanism of sporulation events reported in a recent study with a tropical Ulva species (Carl et al., 2014).

\section{GAMETE PURIFICATION AND AXENIC CULTURE OF U. Iinza AND REOUIREMENT FOR EPIPHYTES}

We have shown that $U$. linza gametes can be purified with the same methodology as developed originally for U. mutabilis gametes, and can germinate parthenogenetically to form new gametophyte thalli, thus paving the way for axenic culture of a second Ulva species. Axenic $U$. linza formed multicellular structures slightly larger than those formed by $U$. mutabilis. This could indicate species-specific differences, or could indicate a small residual (and uncultivable) bacterial load in the culture, that was not detected in the Petri dish test. As 16S PCR was not carried out, we cannot rule out this possibility.

However, when we tested the ability of the two specific bacterial species that rescue morphology in $U$. mutabilis to rescue axenic $U$. linza development, we found that recovery was slow and incomplete, particularly of the rhizoids, despite the clustering of the bacteria around the rhizoids. No filamentous basal system was formed, in contrast to Kapraun's and Flynn's observation with culture studies to E. linza (L.; Kapraun and Flynn, 1973). In summary, epiphytic bacteria are required for both growth and differentiation of $U$. linza, but $U$. linza requires different, although probably related, bacteria to U. mutabilis for normal morphology, particularly of rhizoid and holdfast formation. In particular, the Cytophaga strain releases potentially algae-specific morphogenetic substances inducing rhizoid formation in an auxin-like fashion. It supports Berglund's (1969) studies, which found that growth of E. linza can in principle be stimulated by water-soluble organic substances separated from nutrients, although he did not observe changes in morphology at that time. 
Marshall et al. (2006) isolated approximately 38 unique bacteria from $U$. linza and categorized them according to their morphogenetic activity within 28 days of incubation. Four categories, based on the number of tubular extensions grown from a central callus, were identified. One category holds for axenic cultures and represents a morphotype very similar to the observed axenic morphotype in this study. However, none of the other categories described the complete recovery of morphogenesis, but a combination of the isolated bacteria was not tested. Therefore, the bacteria should be re-isolated from $U$. linza according to the protocol of Marshall et al. (2006) and tested in combinations of the Roseobacter sp. and Cytophaga sp. using the newly established laboratory strains of $U$. linza.

\section{SUMMARY AND FUTURE WORK}

We have shown that $U$. linza sporulation can be induced using the protocols previously developed for U. mutabilis (Stratmann et al., 1996; Wichard and Oertel, 2010; Spoerner et al., 2012), and that $U$. linza likely also produces a SWI, like U. mutabilis. Moreover, both species appear to use similar concepts controlling sporulation, as inhibitors purified from $U$. mutabilis and $U$. linza using identical protocols work largely interchangeably in both species. $U$. linza gametes can be purified for axenic culture and can germinate parthenogenetically, similarly to those from U. mutabilis. Experiments adding back U. mutabilis epiphytic bacteria to axenic $U$. linza gametes suggest the existence of species-specific differences in bacterial signals regulating development, particularly of rhizoids. In future, SI and SWI from U. linza should be further characterized, and the $U$. linza-specific bacteria and signals regulating normal development (particularly the Cytophaga-equivalent affecting rhizoid development) should be identified. Understanding of sporulation in more than one Ulva species will shed light on the formation of green tides (as seen with U. prolifera; Gao et al., 2010). Moreover, development of axenic culture for a second Ulva species potentially enables future comparative studies, particularly of the bacterial signals regulating green seaweed morphogenesis. However, our results also highlight the usefulness of a standardized model culture system using a single species for a detailed understanding of the principles of seaweed development.

\section{ACKNOWLEDGMENTS}

This work was funded by a Royal Society-Leverhulme Trust Senior Research Fellowship (Juliet C. Coates), the Jena School for Microbial Communication, the Collaborative Research Centre 1127 "Chemical Mediators in complex Biosystems" (Thomas Wichard) and the Deutsche Bundesstiftung Umwelt (DBU) (for the Ph.D. fellowship to Ralf W. Kessler), a UK-Natural Environment Research Council Ph.D. studentship to Eleanor F. Vesty, and a Society for In Vitro Biology Philip White travel award to Eleanor F. Vesty. The authors would like to acknowledge networking support by the COST Action "Phycomorph" FA1406 and technical support from Susan J. Bradshaw.

\section{REFERENCES}

Alsufyani, T., Engelen, A. H., Diekmann, O. E., Kuegler, S., and Wichard, T. (2014). Prevalence and mechanism of polyunsaturated aldehydes production in the green tide forming macroalgal genus Ulva (Ulvales, Chlorophyta). Chem. Phys. Lipids 183, 100-109. doi: 10.1016/j.chemphyslip.2014.05.008

Banks, J. A., Nishiyama, T., Hasebe, M., Bowman, J. L., Gribskov, M., dePamphilis, C., et al. (2011). The Selaginella genome identifies genetic changes associated with the evolution of vascular plants. Science 332, 960-963. doi: 10.1126/science. 1203810

Berglund, H. (1969). Stimulation of growth of two marine green algae by organic substances excreted by Enteromorpha linza in unialgal and axenic cultures. Physiol. Plant 22, 1069-1073. doi: 10.1111/j.1399-3054.1969.tb07467.x

Blomster, J., Back, S., Fewer, D. P., Kiirikki, M., Lehvo, A., Maggs, C. A., et al. (2002). Novel morphology in Enteromorpha (Ulvophyceae) forming green tides. Am. J. Bot. 89, 1756-1763. doi: 10.3732/ajb.89.11.1756

Brodie, J., Maggs, C. A., and John, D. M. (2007). Green Seaweeds of Britain and Ireland. Dunmurry: British Phycological Society.

Bruhn, A., Dahl, J., Nielsen, H. B., Nikolaisen, L., Rasmussen, M. B., Markager, S., et al. (2011). Bioenergy potential of Ulva lactuca: biomass yield, methane production and combustion. Bioresour. Technol. 102, 2595-2604. doi: 10.1016/j.biortech.2010.10.010

Callow, J. A., and Callow, M. E. (2006a). "Biofilms," in Antifouling Compounds, eds N. Fusetani and A. S. Clare (Berlin: Springer), 141-171. doi: 10.1007/3-54030016-3_6

Callow, J. A., and Callow, M. E. (2006b). "The spore adhesive system of Ulva," in Biological Adhesives, eds A. M. Smith and J. A. Callow (Berlin: Springer), 63-78.

Carl, C., De Nys, R., Lawton, R. J., and Paul, N. A. (2014). Methods for the induction reproduction in a species of filamentous Ulva. PLoS ONE 9:e97396. doi: 10.1371/journal.pone.0097396

Coudert, Y., Perin, C., Courtois, B., Khong, N. G., and Gantet, P. (2010). Genetic control of root development in rice, the model cereal. Trends Plant Sci. 15, 219226. doi: 10.1016/j.tplants.2010.01.008

Dibenedetto, A. (2012). "Production of aquatic biomass and extraction of bio-oil," in Biorefinery: From Biomass to Chemicals and Fuels, eds M. Aresta, A. Dibenedetto, and F. Dumeignil (Göttingen: De Gruyter), 81-101.

Føyn, B. (1958). Über die Sexualität und den Generationswechsel von Ulva mutabilis. Arch. Protistenk. 102, 473-480.

Fries, L. (1975). Some observations on morphology of Enteromorpha linza (L) Agradh and Enteromorpha compressa (L) Grev in axenic culture. Bot. Mar. 18, 251-253.

Gao, S., Chen, X. Y., Yi, Q. Q., Wang, G. C., Pan, G. H., Lin, A. P., et al. (2010). A strategy for the proliferation of Ulva prolifera, main causative species of green tides, with formation of sporangia by fragmentation. PLoS ONE 5:e8571. doi: 10.1371/journal.pone.0008571

Girin, T., David, L. C., Chardin, C., Sibout, R., Krapp, A., Ferrario-Méry, S., et al. (2014). Brachypodium: a promising hub between model species and cereals. J. Exp. Bot. 65, 5683-5696. doi: 10.1093/jxb/eru376

Goff, S. A., Ricke, D., Lan, T. H., Presting, G., Wang, R., Dunn, M., et al. (2002). A draft sequence of the rice genome (Oryza sativa L. ssp. japonica). Science 296, 92-100. doi: 10.1126/science. 1068275

Guidone, M., Thornber, C., Wysor, B., and O'Kelly, C. J. (2013). Molecular and morphological diversity of Narragansett Bay (RI, USA) Ulva (Ulvales, Chlorophyta) populations. J. Phycol. 49, 979-995. doi: 10.1111/jpy.12108

Hiraoka, M., Shimada, S., Uenosono, M., and Masuda, M. (2004). A new green-tide-forming alga, Ulva ohnoi Hiraoka et Shimada sp nov (Ulvales, Ulvophyceae) from Japan. Phycol. Res. 52, 17-29. doi: 10.1111/j.1440-1835.2004.tb00 311.x

Irish, V. F., and Benfey, P. N. (2004). Beyond Arabidopsis. Translational biology meets evolutionary developmental biology. Plant Physiol. 135, 611-614. doi: 10.1104/pp.104.041632

Kapraun, D. F., and Flynn, E. H. (1973). Culture studies of Enteromorpha linza (L.) J. Ag. and Ulvaria oxysperma (Kützing) Bliding (Chlorophyceae, Ulvales) from Central America. Phycologia 12, 145-152. doi: 10.2216/i0031-8884-12-3145.1

Leliaert, F., Zhang, X. W., Ye, N. H., Malta, E., Engelen, A. H., Mineur, F., et al. (2009). Research note: identity of the Qingdao algal bloom. Phycol. Res. 57, 147-151. doi: 10.1111/j.1440-1835.2009.00532.x

Løvlie, A. (1964). Genetic control of division rate and morphogenesis in Ulva mutabilis Føyn. CR Trav. Lab. Carlsb. Comptes 34, 77-168.

Løvlie, A. (1968). On the use of a multicellular alga (Ulva mutabilis Føyn) in the study of general aspects of growth and differentiation. Nytt. Magasin. Zoolog. 16, 39-49. 
Marshall, K., Joint, I., Callow, M. E., and Callow, J. A. (2006). Effect of marine bacterial isolates on the growth and morphology of axenic plantlets of the green alga Ulva linza. Microb. Ecol. 52, 302-310. doi: 10.1007/s00248-0069060-X

Matsuo, Y., Suzuki, M., Kasai, H., Shizuri, Y., and Harayama, S. (2003). Isolation and phylogenetic characterization of bacteria capable of inducing differentiation in the green alga Monostroma oxyspermum. Environ. Microbiol. 5, 25-35. doi: 10.1046/j.1462-2920.2003.00382.x

Nelson, T. A., Lee, D. J., and Smith, B. C. (2003). Are "green tides" harmful algal blooms? Toxic properties of water-soluble extracts from two bloom-forming macroalgae, Ulva fenestrata and Ulvaria obscura (Ulvophyceae). J. Phycol. 39, 874-879. doi: 10.1046/j.1529-8817.2003.02157.x

Nilsen, G., and Nordby, O. (1975). Sporulation inhibiting substance from vegetative thalli of green alga Ulva mutabilis Foyn. Planta 125, 127-139. doi: 10.1007/BF00388699

Nisizawa, K., Noda, H., Kikuchi, R., and Watanabe, T. (1987). The main seaweed foods in Japan. Hydrobiologia 151, 5-29. doi: 10.1007/BF00046102

Orman-Ligeza, B., Parizot, B., Gantet, P. P., Beeckman, T., Bennett, M. J., and Draye, X. (2014). Post-embryonic root organogenesis in cereals: branching out from model plants. Trends Plant Sci. 18, 459-467. doi: 10.1016/j.tplants.2013.0 4.010

Rensing, S. A., Lang, D., Zimmer, A. D., Terry, A., Salamov, A., Shapiro, H., et al. (2008). The Physcomitrella genome reveals evolutionary insights into the conquest of land by plants. Science 319, 64-69. doi: 10.1126/science.1150646

Rensink, W. A., and Buell, C. R. (2004). Arabidopsis to rice. Applying knowledge from a weed to enhance our understanding of a crop species. Plant Physiol. 135, 622-629. doi: 10.1104/pp.104.040170

Smetacek, V., and Zingone, A. (2013). Green and golden seaweed tides on the rise. Nature 504, 84-88. doi: 10.1038/nature12860

Spannagl, M., Mayer, K., Durner, J., Haberer, G., and Froehlich, A. (2011). Exploring the genomes: from Arabidopsis to crops. J. Plant Physiol. 168, 3-8. doi: 10.1016/j.jplph.2010.07.008

Spoerner, M., Wichard, T., Bachhuber, T., Stratmann, J., and Oertel, W. (2012). Growth and thallus morphogenesis of Ulva mutabilis (Chlorophyta) depends on a combination of two bacterial species excreting regulatory factors. J. Phycol. 48, 1433-1447. doi: 10.1111/j.1529-8817.2012.01231.x
Stratmann, J., Paputsoglu, G., and Oertel, W. (1996). Differentiation of Ulva mutabilis (Chlorophyta) gametangia and gamete release are controlled by extracellular inhibitors. J. Phycol. 32, 1009-1021. doi: 10.1111/j.0022-3646.1996.01009.x

Tabarsa, M., Rezaei, M., Ramezanpour, Z., and Waaland, J. R. (2012). Chemical compositions of the marine algae Gracilaria salicornia (Rhodophyta) and Ulva lactuca (Chlorophyta) as a potential food source. J. Sci. Food Agric. 92, 2500-2506. doi: 10.1002/jsfa.5659

The Arabidopsis Genome Initiative. (2000). Analysis of the genome sequence of the flowering plant Arabidopsis thaliana. Nature 408, 796-815. doi: 10.1038/35048692

Wichard, T., and Oertel, W. (2010). Gametogenesis and gamete release of Ulva mutabilis and Ulva lactuca (Chlorophyta): regulatory effects and chemical characterization of the "swarming inhibitor." J. Phycol. 46, 248-259. doi: 10.1111/j.1529-8817.2010.00816.x

Xu, J., Zhang, X., Ye, N., Zheng, Z., Mou, S., Dong, M., et al. (2013). Activities of principal photosynthetic enzymes in green macroalga Ulva linza: functional implication of C-4 pathway in CO2 assimilation. Sci. China Life Sci. 56, 571-580. doi: $10.1007 / \mathrm{s} 11427-013-4489-\mathrm{x}$

Conflict of Interest Statement: The authors declare that the research was conducted in the absence of any commercial or financial relationships that could be construed as a potential conflict of interest.

Received: 10 November 2014; accepted: 07 January 2015; published online: 26 January 2015.

Citation: Vesty EF, Kessler RW, Wichard T and Coates JC (2015) Regulation of gametogenesis and zoosporogenesis in Ulva linza (Chlorophyta): comparison with Ulva mutabilis and potential for laboratory culture. Front. Plant Sci. 6:15. doi: 10.3389/fpls.2015.00015

This article was submitted to Plant Evolution and Development, a section of the journal Frontiers in Plant Science.

Copyright (C) 2015 Vesty, Kessler, Wichard and Coates. This is an open-access article distributed under the terms of the Creative Commons Attribution License (CC BY). The use, distribution or reproduction in other forums is permitted, provided the original author(s) or licensor are credited and that the original publication in this journal is cited, in accordance with accepted academic practice. No use, distribution or reproduction is permitted which does not comply with these terms. 